ISSN : 2252-3839 (Print)

ISSN : 2549-2403 (On Line)

DOI : 10.28989/compiler.v9i1.627

http://ejournals.stta.ac.id/index.php/compiler/

\title{
APPLICATION FOR CONTROL OF DISTANCE LIGHTS USING MICROCONTROLLER NODEMCU ESP 8266 BASED ON INTERNET OF THINGS (IoT) \\ Rama Sahtyawan $^{1}$, Arief Ikhwan Wicaksono \\ ${ }^{1,2}$ Program Studi Teknologi Informasi
}

Fakultas Teknik dan Teknologi Informasi, Universitas Jenderal Achmad Yani Yogyakarta

Jl. Siliwangi Km 0.7, Banyuraden, Gamping, Sleman, Yogyakarta

Email : ${ }^{1}$ ramasahtyawan@gmail.com, ${ }^{2}$ ariefikhwanwicaksono@gmail.com

\begin{abstract}
Control systems in the field of technology, electronic devices must be controlled. But there are still those who oppose if the room does not have a place anywhere, where there is no one at home, other people forget to change the lights, it is very inconvenient if you have to go home, even though if the lights are left activated there will be a waste, from which It was stated that a light monitoring device was provided using the Internet-based (IoT) tea-based Relay module using the NodeMcu ESP 8266 microcontroller which has been equipped with a wifi module, so that the led lights can be monitored by the user in realtime so using the IoT Program platform using the Blynk application, which can be controlled via handphone, In the system implementation, a display is made using Blynk. There are 4 on and off switch buttons which are used to facilitate and activate the Led lights. In this research, the control of Led using blynk is done 10 times. Led control testing is used to see each procedural function running correctly as expected, the results of tests that have been done get the results of $10 x$ experiments that have been done to get $2 x$ interrupted experiments in the LEDs needed to connect the wifi network
\end{abstract}

Keywords: NodeMCU ESP 8266, Relay, (IoT), Blynk, Led

\section{Latar Belakang Masalah}

Sistem pengendalian merupakan hal yang penting di bidang teknologi. Banyaknya peralatan elektronik yang harus dikendalikan. Namun memiliki kendala jika ruang kendali ada di beberapa tempat, sehingga untuk mengendalikan peralatan elektronik tersebut[1], seseorang harus berpindah dari satu tempat pengendalian ke tempat pengendalian berikutnya, cara seperti ini akan memakan banyak waktu [2]. Sebagai solusi IoT yang membantu manusia untuk lingkungan dalam ruangan, dengan adanya rumah pintar untuk meningkatkan kualitas hidup orang-orang ketika mereka tinggal didalam rumah[3].dan terciptanya a smart building automation system[4], yang memiliki keamanan wireless di rumah tersebut[5]. Penggunaan embedded system juga digunakan untuk Application of Case Based Reasoning for Student Recommendations Drop Out[9]. Keywords Search Correction Using Damerau Levenshtein Distance Algorithm[10]. Metode Nilai Jarak guna Kesamaan Ciri suatu Citra[11].

Pada kasus pengendalian pada lampu, misalnya saat seseorang meninggalkan rumah, ternyata orang tersebut lupa mematikan salah satu lampu listrik yang ada di rumahnya[6].maka diperlukan desain arsitektur jaringan untuk mendukungnya[7] Jika hal ini terjadi akan sangat merepotkan jika orang tersebut harus kembali ke rumah hanya untuk mematikan lampu. jika dibiarkan lampu menyala, maka ini merupakan suatu pemborosan[8].

Dari permasalahan diatas, maka diperlukan platform internet of things (IoT) yang menghubungkan antar benda apapun yang dapat terhubung, yang tidak hanya menghubungkan antar manusia, akan tetapi mampu menyimpan project serta mendukung 
berbagai mikrokontroler. Perpaduan antara internet dan peralatan elektronika membutuhkan platform untuk bisa terkolaborasi. Blynk ialah salah satu interface internet of things (IoT) yang user-friendly dan memiliki koneksi mikrokontroler yang dihubungkan dengan internet.

Penelitian ini akan dikembangkan sebuah perangkat menggunakan mikrokontroller NodeMcu ESP 8266 yang merupakan modul wifi serba bisa yang dirancang sebuah sistem kendali untuk membuka atau menutup relay sebagai pengganti saklar dengan memanfaatkan platform IoT Blynk. Data keluaran Led tersebut akan secara real-time dapat dipantau kepada pengguna yang bersangkutan melalui aplikasi mobile. Hasil dari perancangan adalah sistem kontrol lampu Led menggunakan Relay yang dapat dikendalikan melalui platform IoT Blynk.

\section{Metodologi Penelitian}

Penelitian ini bermula dengan melakukan telaah pada permasalahn yang akan diselesaikan kemudian melakukan analisis dan pemetaan solusi dengan menggunakan sumber daya yang sesuai dan tersedia. Penelitian ini dilakukan dengan menerapkan Internet of Things (IoT) untuk kontrol lampu Led dengan modul Relay. Hasil dari penelitian ini diharapkan dapat memberikan kontribusi bagaimana cara kontrol lampu Led menggunakan Blynk.

Tabel 1 Tahapan Penelitian

\begin{tabular}{|c|c|c|c|}
\hline No & Tahap & Langkah & Indikator \\
\hline 1 & $\begin{array}{l}\text { Identifikasi } \\
\text { dan analisis } \\
\text { kebutuhan }\end{array}$ & $\begin{array}{l}\text { a) Melakukan konfigurasi } \\
\text { dan ujicoba pemasangan } \\
\text { modul relay sebagai } \\
\text { saklar } \\
\text { b) Membuat program } \\
\text { arduino untuk akuisisi } \\
\text { data secara real-time dari } \\
\text { modul relay yang } \\
\text { terpasang }\end{array}$ & $\begin{array}{l}\text { a) modul relay yang akan } \\
\text { digunakan sebagai } \\
\text { saklar, membuka dan } \\
\text { menutup arus keluaran } \\
\text { lampu } \\
\text { b) Program arduino yang } \\
\text { dibuat bisa menangkap } \\
\text { perubahan data secara } \\
\text { real-time }\end{array}$ \\
\hline 2 & Desain sistem & $\begin{array}{l}\text { a) membuat desain sistem } \\
\text { menjelaskan susunan } \\
\text { sistem secara keseluruhan } \\
\text { b) membuat mekanisme } \\
\text { transfer data secara real- } \\
\text { time antara perangkat } \\
\text { modul relay dengan } \\
\text { blynk }\end{array}$ & $\begin{array}{l}\text { a) mobile application } \\
\text { yang dikembangkan } \\
\text { bisa menampilkan data } \\
\text { mentah dan perubahan } \\
\text { data secara real-time } \\
\text { yang dihasilkan oleh } \\
\text { perangkat dalam } \\
\text { interval kurang dari } 5 \\
\text { detik }\end{array}$ \\
\hline 3 & $\begin{array}{l}\text { Implementasi } \\
\text { Sistem }\end{array}$ & 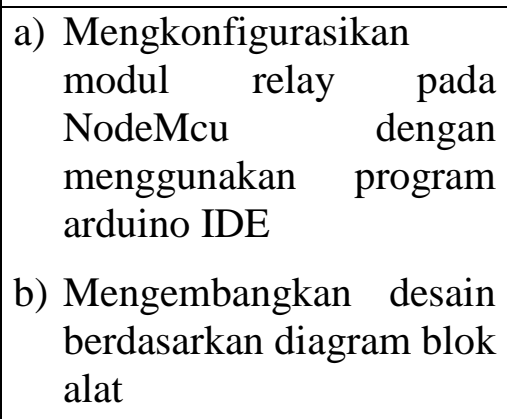 & $\begin{array}{l}\text { a) Modul Relay dapat } \\
\text { mengirimkan data } \\
\text { dengan konsisten dan } \\
\text { akurat ke mobile } \\
\text { application. } \\
\text { b) Mobile application } \\
\text { dapat secara realtime } \\
\text { menampilkan }\end{array}$ \\
\hline 4 & Pengujian & $\begin{array}{ll}\text { a) Melakukan } & \text { pengujian } \\
\text { modul relay } & \text { membuka }\end{array}$ & dikirimkan oleh relay. \\
\hline
\end{tabular}




\begin{tabular}{|l|l|l|r|}
\hline Sistem & $\begin{array}{l}\text { dan menutup arus, } \\
\text { keluaran mati/hidupnya } \\
\text { Led. }\end{array}$ & $\begin{array}{c}\text { c) Mobile application } \\
\text { menampilkan notifikasi } \\
\text { apabila lampu on/off } \\
\text { dan re-confirguration. }\end{array}$ \\
& $\begin{array}{l}\text { b) Melakukan perbaikan } \\
\text { pada bug-bug yang } \\
\text { ditemukan. }\end{array}$ & \\
& & \\
\hline
\end{tabular}

\subsection{Arsitektur Sistem}

Pada arsitektur sistem menjelaskan tentang perancangan dari sistem tersebut yang terdiri atas NodeMcu ESP 8266, Relay, HP Android, aplikasi blynk, router, adapun gambar arsitektur sistemnya sebagai berikut :

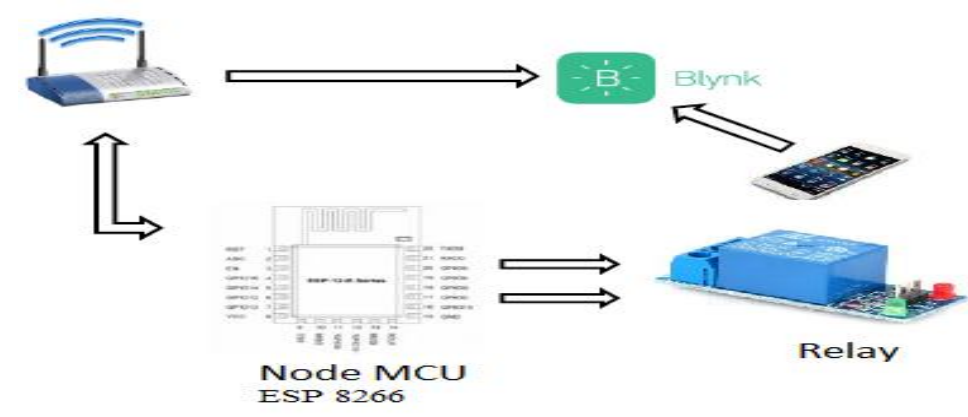

Gambar 1 Rancangan arsitektur system

Gambar 1 menjelaskan susunan sistem secara keseluruhan bahwa bagian masukkan terdiri atas NodeMcu ESP 8266, Relay, HP Android, aplikasi blynk, router. NodeMcu mempunyai perangkat Modul Wifi ESP8266 yang digunakan sebagai alat komunikasi data ke seluruh elemen control. Android sebagai antarmuka antara pengguna dengan mikrokontroller untuk menyalakan atau mematikan lampu (membuka atau menutup relay) melalui aplikasi blynk. Modul Relay, digunakan sebagai saklar. Berfungsi membuka dan menutup arus sebagai keluaran mati/hidup lampu yang dikendalikan melalui aplikasi android

\subsection{Perangkat Keras.}

Didalam Perancangan sebuah perangkat keras terdiri dari input dan output yang mengubah tegangan AC menjadi DC, adapun gambar rangkaian perangkat kerasnya sebagai berikut :

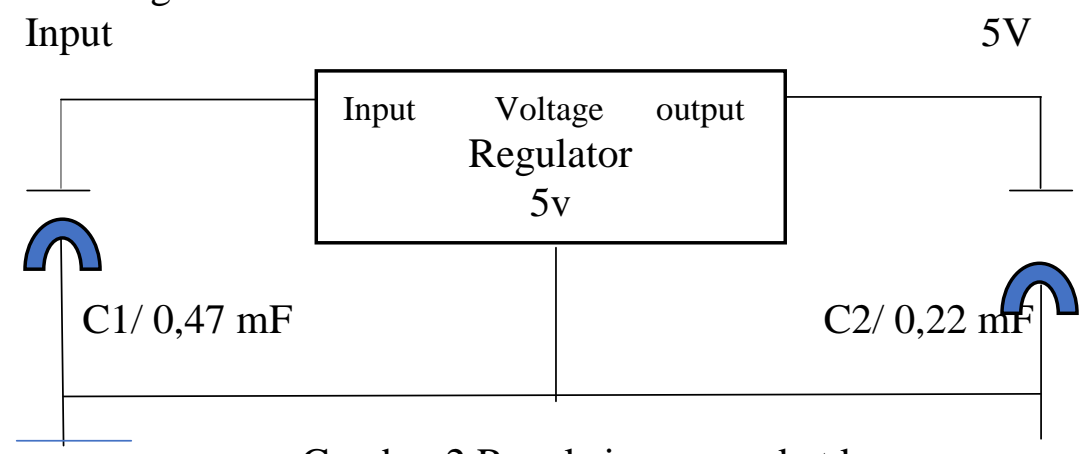

Gambar 2 Rangkaian perangkat keras 
Pada Gambar 2 menjelaskan rangkaian perangkat keras terdiri atas power supply, NodeMcu, modul Relay. Ketiganya saling terkait, pada regulator terdiri atas input ( $\mathrm{C} 1 / 0,47$ $\mathrm{mF}$ ) voltage dan output yang menghasilkan output tegangan $5 \mathrm{v}$. NodeMcu terhubung dengan modul relay sebagai saklar yang digunakan sebagai hidup/matinya pengontrolan lampu, NodeMcu terhubung dengan power supply yang berfungsi untuk mengubah tegangan AC menjadi DC sebelum didistribusikan pada NodeMcu.

\section{Hasil dan Pembahasan}

Objek yang akan digunakan didalam pengujian ini menggunakan Led (Light Emitting Dioda), adapun gambarnya sebagai berikut.

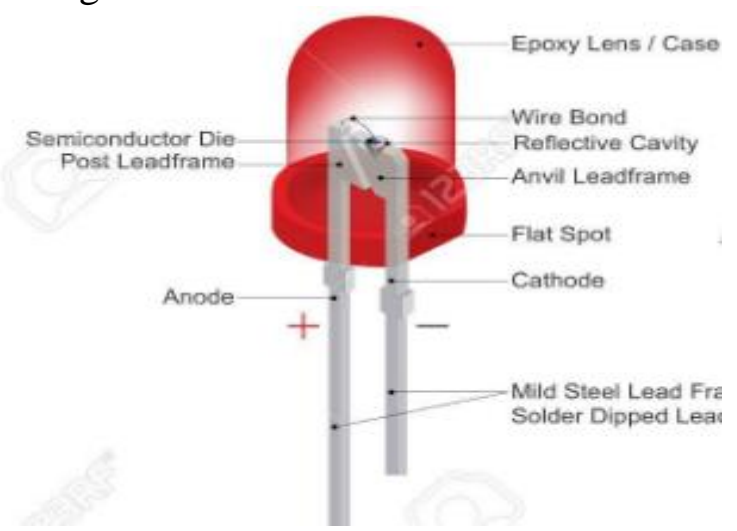

Gambar 3 LED (Light Emitting Dioda).

Pada gambar 3 Led (Light Emitting Dioda) merupakan dioda yang dapat mengeluarkan cahaya dan menghantarkan arus listrik searah. Cahaya yang dipancarkan Led dapat terjadi apabila dihantarkan tegangan listrik pad arus $20 \mathrm{~mA}$. Pada Led terdapat kaki berjumlah 2 buah yaitu kaki katoda dan kaki anoda.

\subsection{Implementasi Sistem}

Didalam mengendalikan lampu menggunakan Nodemcu dengan modul relay terhubung menggunakan daya 5v. Pada aplikasi blynk digunakan sebagai pendukung HP Smartphone untuk mengatur lampu Led pada kondisi ON (nyala) dan OFF (mati). Pada NodeMcu ESP 8266 akan tampil outputnya menampilkan light switch berwarna kuning menunjukkan Led pada kondisi menyala, adapun tampilan perangkatnya sebagai berikut:

\begin{tabular}{|c|c|c|c|}
\hline \multicolumn{2}{|c|}{ Tampilan Program Blynk di HP } & \multicolumn{2}{c|}{ Tampilan NodeMCU ESP 8266 } \\
\hline & & & \\
\hline
\end{tabular}


Application For Control Of Distance Lights Using Microcontroller...

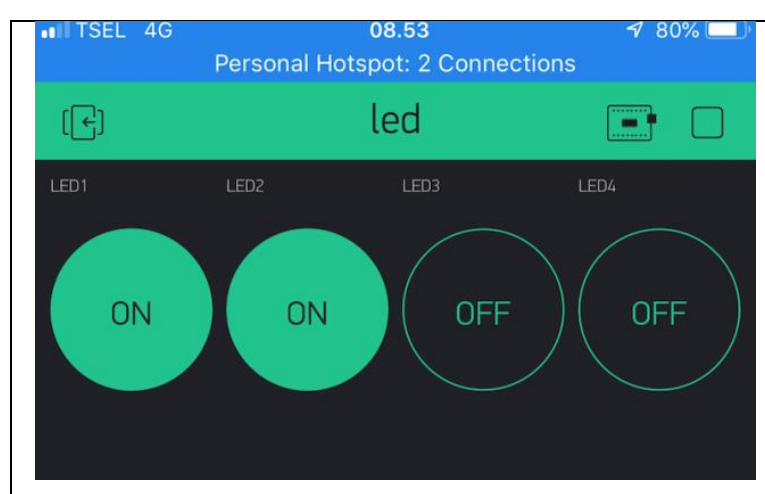

Tombol Led 1,2 On

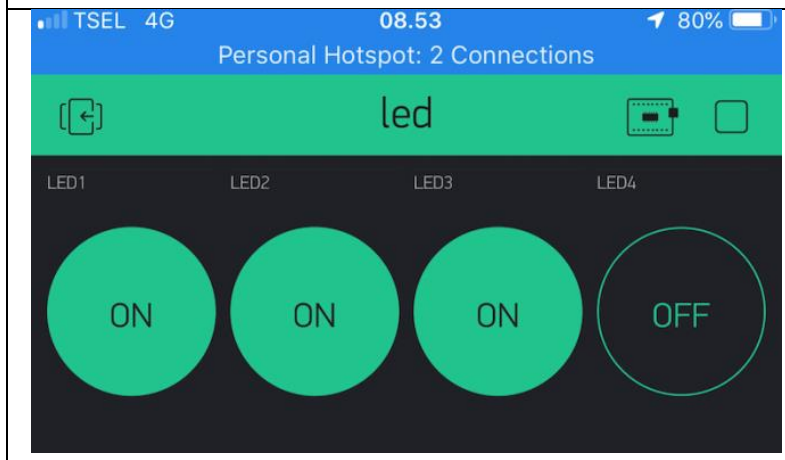

Tombol Led1,2,3 On

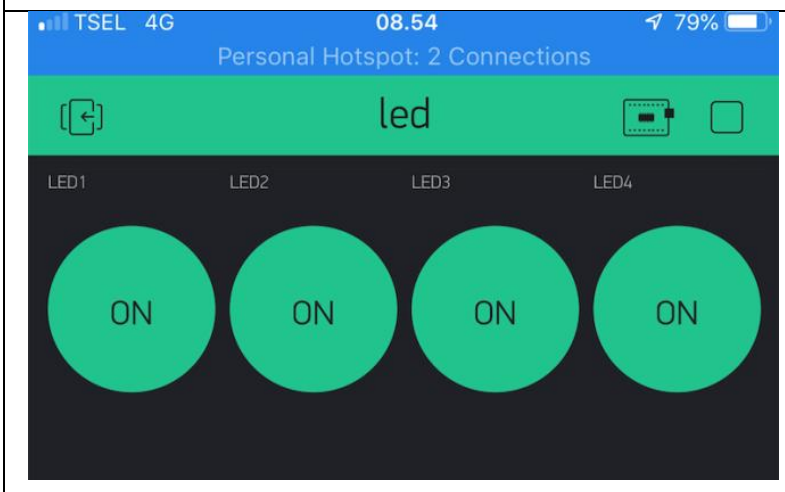

Tombol Led 1,2,3,4 On

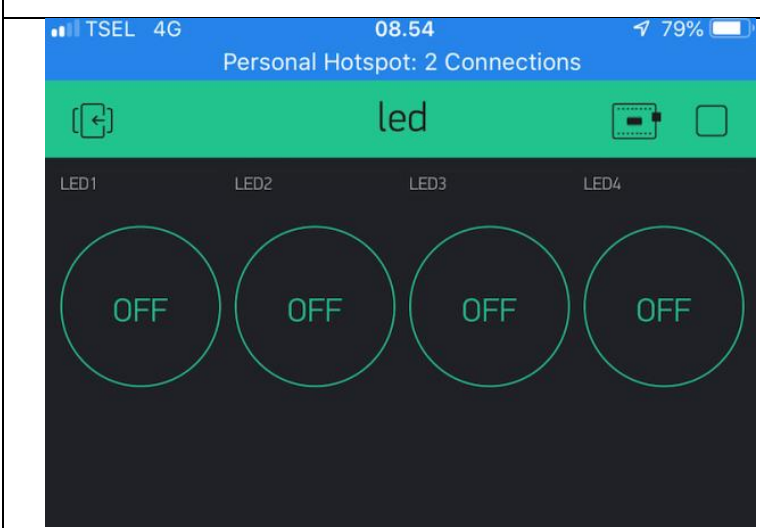

Tombol Led 1,2,3,4 semua Off

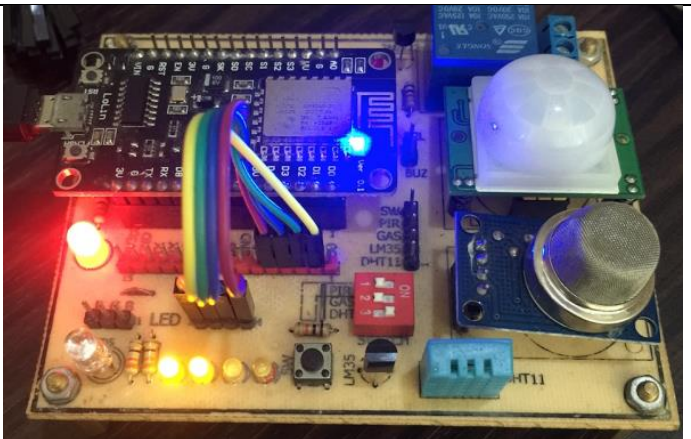

Led 1,2 Menyala

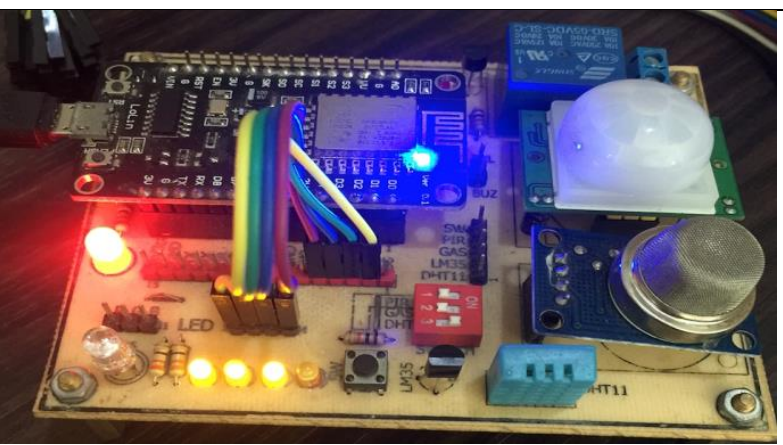

Led 1,2,3 Menyala

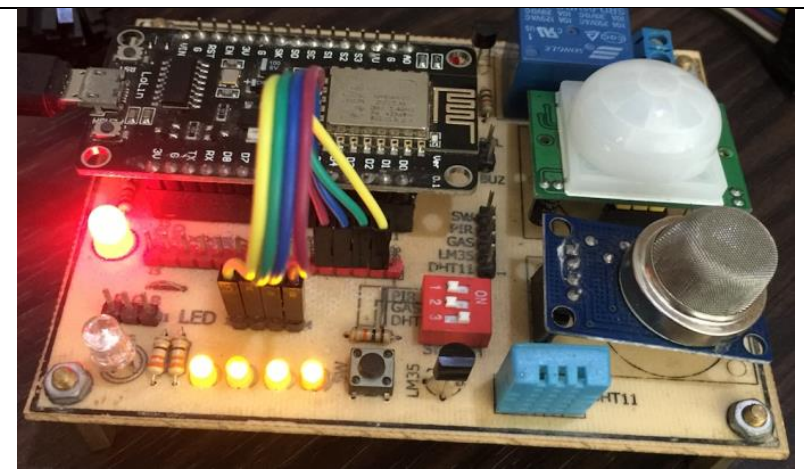

Led 1,2,3,4 Menyala

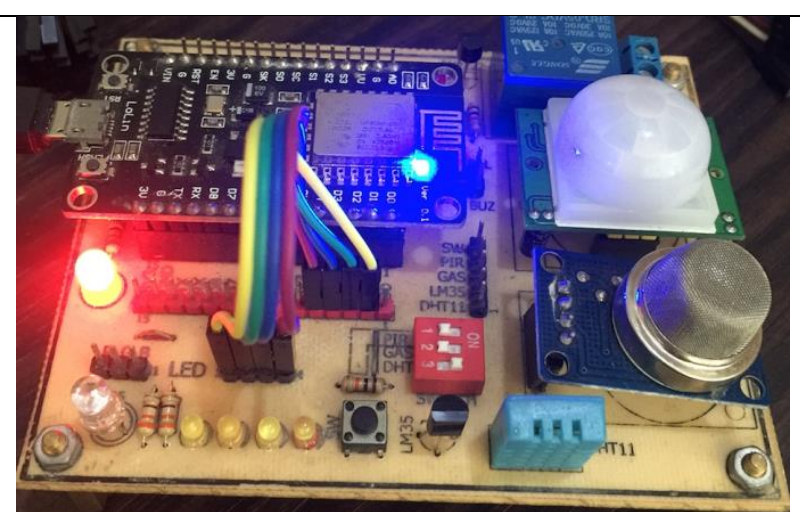

Led 1,2,3,4 semua Mati

Gambar 4 Tampilan Blynk dan NodeMCU ESP 8266. 
Pada gambar 4 Tampilan Blynk yang terdapat pada Handphone, pada Tombol Led 1 On, Led 2,3,4 Off, maka output pada NodeMcu ESP 8266 tersebut, akan menampilkan output Led 1 = Menyala, Led 2,3,4 = mati. Pada Tombol Led 1,2 = On, Led 3,Led 4 Off, maka output pada NodeMcu ESP 8266 tersebut, akan menampilkan output Led 1, Led2 = Menyala, Led 3,4 = mati. Pada Tombol Led 1,2,3 = On, Led 4 Off, maka output pada NodeMcu ESP 8266 tersebut, akan menampilkan output Led 1,2,3 = Menyala, Led $4=$ mati.

Pada aplikasi Blynk dan NodeMcu ESP 8266 memerlukan pengkodean program dengan menggunakan konfigurasi Arduino IDE, adapun tampilannya sebagai berikut :

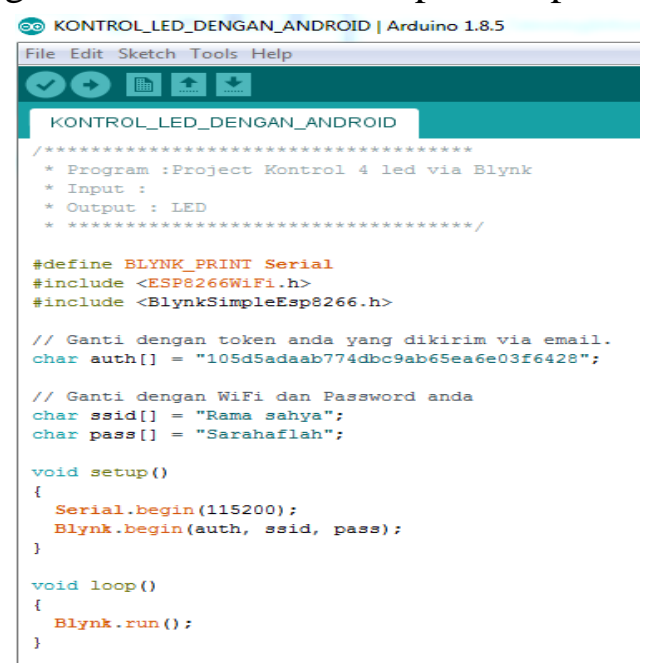

\section{Gambar 5 Arduino IDE}

Pada gambar 5 Program Arduino IDE, sistem akan memproses input dari relay untuk mengkontrol Led tersebut. Pada pengkodeannya memerlukan token yang dikirimkan melalui email, dan diperlukan setting wifi user dan passwordnya, dan beberapa sintaks untuk pemanggilan led dan void loop pada blynk dijalankan.

\subsection{Pengujian dan Evaluasi Sistem.}

Dalam penelitian ini dilakukan pengujian kontrol Led menggunakan blynk sebanyak 10kali. Pengujian kontrol Led digunakan untuk melihat setiap prosedural fungsi berjalan dengan benar sesuai yang diharapkan, adapun hasil pengujiannya sebagai berikut:

Tabel 2 Hasil Pengujian

\begin{tabular}{|l|c|c|c|c|c|c|c|c|c|}
\hline \multirow{2}{*}{ No } & \multicolumn{4}{|c|}{ Pengujian Blynk } & \multicolumn{3}{c|}{ Output led NodeMcu } & Status \\
\cline { 2 - 10 } & switch & switch & switch & switch & led & led & led & led & Koneksi \\
\cline { 2 - 9 } & 1 & 2 & 3 & 4 & 1 & 2 & 3 & 4 & Wifi \\
\hline 1 & ditekan & - & - & - & nyala & mati & mati & mati & terkoneksi \\
\hline 2 & - & ditekan & - & - & mati & nyala & mati & mati & terkoneksi \\
\hline 3 & - & ditekan & - & - & mati & nyala & mati & mati & terkoneksi \\
\hline 4 & - & & - & ditekan & mati & mati & mati & mati & terputus \\
\hline 5 & - & - & ditekan & - & mati & mati & nyala & mati & terkoneksi \\
\hline
\end{tabular}




\begin{tabular}{|l|l|l|l|l|l|l|l|l|l|}
\hline 6 & ditekan & ditekan & - & - & nyala & nyala & mati & mati & terkoneksi \\
\hline 7 & ditekan & - & ditekan & - & nyala & mati & nyala & mati & terkoneksi \\
\hline 8 & ditekan & - & ditekan & ditekan & nyala & mati & mati & mati & terputus \\
\hline 9 & - & ditekan & ditekan & - & mati & nyala & nyala & mati & Terkoneksi \\
\hline 10 & ditekan & ditekan & ditekan & - & nyala & nyala & nyala & mati & Terkoneksi \\
\hline
\end{tabular}

Dari tabel 2 pada skenario pengujian yang sudah dikerjakan mendapatkan hasil dari 10x melakukan percobaan yang sudah dikerjakan, pada pengujian blynk terdiri dari 4 switch, yang menghasilkan output pada led 1,2,3,4 dan akan menghasilkan led menyala dan mati sesuai dengan input pada tombol switchnya. Dari pengujian diatas didapatkan 2 x percobaan terputus dalam Led disebabkan hilangnya koneksi jaringan wifi tersebut.

\subsection{Kesimpulan}

Pada implementasi NodeMcu esp8266 untuk kontrol Led ini telah berjalan dengan baik dimana:

a. Nodemcu dapat menerima semua masukkan dari sensor relay, Nodemcu dapat mengontrol relay lampu Led.

b. Aplikasi Blynk dapat dikoneksikan dengan Nodemcu sehingga pengkontrolan mematikan atau mengaktifkan Led menggunakan sensor relay lebih mudah dipantau menggunakan HP.

\section{Daftar Pustaka}

[1] Kairul (2017). The Internet of Things (IoT) in Information Agencies; International Journal of Academic Research in Business and Social Sciences;IJARBSS;Vol. 8 , No. 9, Sept. 2018, E-ISSN: 2222-6990 @ 2018 HRMARS

[2] Kortuem, G., Kawsar, F., Fitton., D., Sundramoorthy, V, (2010), Smart objects as building blocks for the internet of things. Internet Computing, IEEE, vol. 14, no.1, 44-5 .

[3] Lin K, Chen M, Deng J, Hassan MM, Fortino G (2016) Enhancedfingerprinting and trajectory prediction for iot localization in smartbuildings. IEEE Trans Autom Sci Eng 13(3):1294-1307.

[4] Chasta, R., Singh, R., Gehlot, A., Mishra, R. G., \& Choudhury, S. (2016). A Smart Building Automation System. International Journal of Smart Home.

[5] Omprakash, K. S. (2011). Wireless Home Security System With Mobile. International Journal of Advanced Engineering Technology.

[6] Furdik, K., Lukac, G., Sabol, T., \& Kostelnik, d. P. (2013). The Network Architecture Design for an Adaptable IoT-based Smart Office Solution. International Journal of Computer Networks and Communications Security.

[7] Farisqi Panduardi, Endi Sailul Haq, (2016). Wireless Smart Home System Menggunakan Raspberry Pi Berbasis Android. Jurnal Teknologi Informasi dan Terapan, Vol. 03, No. 01, Juli-Desember 2016 ISSN:2354-838X.

[8] Budi. A \& Fredi.S, (2017) LED control system with cayenne framework for the Internet of Things (IoT); Vol.2, No.1, Juni 2016. 
[9] Agustian, H. (2019, December). Application of Case Based Reasoning for Student Recommendations Drop Out (Case Study: Adisutjipto College of Technology). In Conference SENATIK STT Adisutjipto Yogyakarta (Vol. 5, pp.159-166).

[10] Oktaviyani, E. D., Christina, S., \& Ronaldo, D. (2019, December).Keywords Search Correction Using Damerau Levenshtein Distance Algorithm. In Conference SENATIK STT Adisutjipto Yogyakarta (Vol. 5, pp. 167-176).

[11] Nugraheny, D. (2015). Metode Nilai Jarak guna Kesamaan atau Kemiripan Ciri suatu Citra (kasus deteksi awan cumulonimbus menggunakan principal component analysis). Angkasa: Jurnal Ilmiah Bidang Teknologi, 7(2), 21-30 